\title{
Conhecendo o uso do genograma entre enfermeiras de unidades pediátricas de um Hospital Universitário
}

Knowing the use of the genogram among nurses of pediatric units of a University Hospital

Conociendo el uso del genograma entre enfermeras de unidades pediátricas de un Hospital Universitario

Cintia Cristina Rodrigues do Vale ${ }^{1}$ (D) https://orcid.org/0000-0001-7497-3065

Nanci Cristiano Santos ${ }^{1}$ (D) https://orcid.org/0000-0002-7015-6217

Margareth Angelo ${ }^{2}$ (D) https://orcid.org/0000-0003-3039-3880

\section{Resumo}

Objetivo: Conhecer a experiência dos enfermeiros de um hospital universitário quanto ao cuidado centrado na família e a inserção do genograma no cotidiano de trabalho em pediatria.

Métodos: Estudo qualitativo, com coleta de dados realizada por meio de entrevistas com 8 enfermeiras de unidades Pediátricas e submetidos a análise de conteúdo.

Resultados: Foram identificadas 4 categorias: a percepção do cuidado centrado na família e a instituição, utilizando o genograma, vantagens do uso do genograma e barreiras e desafios para o uso do genograma.

Conclusão: Os enfermeiros consideram importante a implementação do cuidado centrado na família e a utilização do genograma na rotina de trabalho. 0 estudo apontou a necessidade de treinamentos continuados da equipe de enfermagem sobre o tema para a superação das dificuldades da implantação do genograma na prática clínica coerente com a abordagem centrada na família.

\section{Abstract}

Objective: To know the experience of nurses in a University Hospital regarding family-centered care and the use of the genogram in the daily work of pediatrics.

Methods: Qualitative study, with data collection carried out through interviews with 8 nurses from pediatric units. Data analysis was guided by content analysis

Results: Four categories were identified: the perception of family care centered and the institution, using the genogram, advantages of using the genogram and barriers and challenges for the use of the genogram.

Conclusion: Nurses consider the implementation of family-centered care and the use of the genogram in the work routine important. The study pointed out the need for continuous training of the nursing team on the subject to overcome the difficulties of implantation of the genogram in clinical practice consistent with the family-centered approach.

\section{Resumen}

Objetivo: Conocer la experiencia de las enfermeras en un Hospital Universitario sobre la atención centrada en la familia y el uso del genograma en el cotidiano de trabajo en pediatría.

Método: Estudio cualitativo, con recolección de datos a través de entrevistas con 8 enfermeras de unidades pediátricas. El análisis de datos fue guiado por el análisis de contenido

Resultados: Se identificaron 4 categorías: la percepción del cuidado centrado en la familia y la institución, utilizando el genograma, ventajas del uso del genograma y las barreras y desafíos para el uso del genograma.

Conclusión: Los enfermeros consideran importante la implementación del cuidado centrado en la familia y la utilización del genograma en la rutina de trabajo. El estudio señaló la necesidad de entrenamientos continuados del equipo de enfermería sobre el tema para la superación de las dificultades de la implantación del genograma en la práctica clínica consistente con el enfoque centrado en la familia.

\section{Como citar:}

Vale CC, Santos NC, Angelo M. [Knowing the use of the genogram among nurses of pediatric units of a University Hospital]. Rev Soc Bras Enferm Ped. 2019;19(1):23-31. Portuguese

\section{Descritores}

Enfermagem Pediátrica; Cuidado centrado na família; Enfermagem; Pediatria; Genograma

\section{Keywords}

Pediatric Nursing; Family centered care; Nursing; Pediatrics; Genogram

\section{Descriptores}

Enfermería Pediátrica; Cuidado centrado en la família; Enfermería; Pediatría; Genograma 


\section{Introdução}

O genograma é uma ferramenta útil no ambiente pediátrico para o enfermeiro, e pode ser considerado o primeiro passo na prática clínica para o estabelecimento de vínculos com a criança e com a família, o reconhecimento da estrutura familiar e sua rede de apoio, além de contribuir com informações necessárias para que o enfermeiro possa avaliar e realizar intervenções com a criança e sua família durante a hospitalização.

Para os enfermeiros, envolver a família nos cuidados, significa uma mudança da prática clínica, pois é necessário que estejam aptos a avaliar e intervir nas famílias, e esse processo se dá por meio do estabelecimento de relacionamentos colaborativos mútuos, permitindo que o enfermeiro alcance com mais competência, os conhecimentos e habilidades clínicas necessárias para realizar a entrevista com as famílias. ${ }^{(1)}$

No momento em que um membro da família, sobretudo quando se trata de uma criança, é hospitalizado, o funcionamento da família é alterado, pois o membro doente passa a ser prioridade no cuidado familiar. A família, vivencia experiências novas, como lidar com o diagnóstico, sentimentos e angústias, adaptação ao ambiente hospitalar e suas regras, além das preocupações existentes ao ter a vida dividida entre sua casa e o hospital. ${ }^{(2)}$

Por isso, é necessário que os profissionais de saúde ampliem o foco do cuidado para além da criança, e voltem a atenção também às necessidades das famílias. Para que isso aconteça, é importante que os profissionais ponderem em sua prática de trabalho a diversidade da dinâmica familiar, a realidade socioeconômica e cultural em que vivem, e a complexidade das dimensões envolvidas na vida dessas pessoas. ${ }^{(3)}$

O genograma é uma ferramenta desenvolvida com o objetivo de avaliar, planejar e intervir nas famílias, além de ajudar os enfermeiros e famílias a terem uma visão ampla dos problemas tanto no contexto histórico, quanto no atual. ${ }^{(1)}$ É um instrumento importante para a avaliação da composição familiar e das relações internas e externas, utilizado por profissionais da saúde para compreender os processos familiares. ${ }^{(4)}$

Na prática da enfermagem, o genograma é utilizado como uma ferramenta clinicamente relevante, e não somente como um mapa ou uma folha de coleta de dados. Os enfermeiros devem ter consciência da finalidade de coletar informações sobre a família e de como essas informações serão úteis para o planejamento da assistência de enfermagem. ${ }^{(1)}$

Estudos apontam a importância do uso do genograma como um instrumento que fornece uma aproximação do enfermeiro com a família, o que contribui de forma positiva na identificação das necessidades dessa família e na possibilidade de o profissional identificar de qual forma poderá ajudar esse grupo familiar. ${ }^{(3,4)}$

Durante os estágios vividos no processo de formação especializada, em instituição que vem direcionando suas ações para a abordagem do cuidado centrado na criança e na família destacam-se a orientação e o incentivo para a inserção do genograma como um instrumento complementar na entrevista do enfermeiro com as famílias.

Este incentivo é coerente com a ideia de que o cuidado centrado na família traz resultados benéficos para a instituição e paciente, como por exemplo, a melhora na satisfação do paciente, família e profissionais de saúde, na comunicação entre a família e os profissionais, envolvimento da família nos cuidados, redução da ansiedade, estresse e depressão nos membros da família de pacientes hospitalizados, tempo de internação, custos e conflitos entre profissionais e familiares. ${ }^{(5)}$

Considerando que o êxito para a implantação do cuidado centrado na família depende da plena integração de instrumentos como o genograma à prática clínica dos enfermeiros, motivamo-nos a explorar esta experiência, à partir do questionamento: "Qual a percepção e a experiência dos enfermeiros quanto a inserção do genograma no cotidiano de trabalho, norteado pelo cuidado centrado na família, nos diferentes cenários de atenção pediátrica?".

O objetivo deste estudo foi conhecer a experiência de enfermeiros de um hospital universitário quanto ao cuidado centrado na família e a inserção do genograma no cotidiano de trabalho em pediatria.

\section{Métodos}

Trata-se de uma pesquisa exploratória com abordagem qualitativa. Neste tipo de pesquisa, o interesse do pesquisador volta-se para a busca do significado das coisas, porque este tem um papel organizador nos seres humanos. Nos settings da saúde em par- 
ticular, conhecer as significações dos fenômenos do processo saúde-doença é essencial para realizar as seguintes coisas: melhorar a qualidade da relação profissional-paciente-família-instituição. ${ }^{(6)}$

Este estudo foi realizado nas unidades pediátricas de um Hospital Universitário na cidade de São Paulo. A população deste estudo foi constituída por enfermeiros e enfermeiros residentes de um Programa de Residência de Enfermagem em Saúde da Criança e do Adolescente, que atuavam nas áreas pediátricas do hospital: Pronto Socorro Infantil, Clínica Pediátrica e Unidade de Terapia Intensiva Pediátrica e Neonatal.

Os critérios de inclusão foram atuar no mínimo por 5 meses nas unidades pediátricas selecionadas, e realizar a prática de cuidados à criança no cotidiano do trabalho. Os dados foram coletados por meio de entrevistas individuais conduzidas por uma das autoras, guiadas por um roteiro semiestruturado composto por 14 perguntas abertas relacionadas ao cuidado centrado na família e ao uso do genograma, como: Você se sente confiante para realizar o Cuidado Centrado na Família em sua unidade? Por que?; Como tem sido a experiência de inserção do genograma no cotidiano de trabalho da sua clínica? Que dificuldades você identifica na inserção do genograma no cotidiano de trabalho de sua clínica? As entrevistas foram realizadas na instituição em outubro de 2018, e tiveram duração média de 15 minutos. As entrevistas foram transcritas na íntegra e identificadas pela letra E (enfermeiras) e ER (Enfermeiras Residentes) por números ordinais de acordo com a ordem de realização. Os dados foram submetidos à análise de conteúdo, ${ }^{(7)}$ gerando as categorias e subcategorias finais.

O estudo foi conduzido segundo os aspectos éticos descritos na Resolução do Conselho Nacional de Saúde 466/2012. Foi aprovado pelo Comitê de Ética em Pesquisa da instituição proponente e da instituição coparticipante da pesquisa sob os pareceres números 2.607.080 e 2.662 .355 respectivamente.

\section{Resultados}

Participaram da entrevista oito enfermeiras, com idade variando entre 25 e 55 anos. Em relação à formação, três eram enfermeiras residentes, três tinham especialização e duas mestrado. As enfermeiras atuavam nas
Clínica Pediátrica (3), Unidade de Terapia Intensiva Pediátrica e Neonatal (3) e Pronto Socorro Infantil (1). A análise dos dados permitiu a identificação de quatro categorias relacionadas à percepção do enfermeiro em relação ao cuidado centrado na família e a utilização do genograma para o planejamento da assistência de enfermagem: a percepção do cuidado centrado na família e a instituição, utilizando o genograma, vantagens do uso do genograma e barreiras e desafios para o uso do genograma.

\section{A PERCEPÇÃO DO CUIDADO CENTRADO NA FAMÍLIA E A INSTITUIÇÃO.}

\section{Importância do Cuidado Centrado na Família}

As enfermeiras consideram importante a utilização de princípios do Cuidado Centrado na Família no cotidiano de trabalho e no planejamento da assistência de enfermagem, pois permite estender o cuidado para além do paciente, abrangendo a família e suas necessidades, levando em consideração a sua complexidade e diversidade.

\section{a) Apoio e suporte a família}

Para as enfermeiras, conhecer as famílias atendidas em seu serviço de saúde, as suas demandas e as suas necessidades, reconhecer a família como uma unidade completa de cuidado e envolvê-la no planejamento da assistência de enfermagem é indispensável, pois a partir do momento em que a estrutura familiar é conhecida pelos profissionais e suas necessidades manifestadas, é possível oferecer suporte e apoio necessários durante o período de internação, atendendo as suas demandas de cuidado. Envolver a família no cuidado e no planejamento da assistência, oferecer autonomia na tomada de decisão, atender as suas demandas e necessidades de cuidado são ações fundamentais para o estabelecimento de vínculo entre família e profissional.

“... a gente tem que considerar que não só o paciente, precisa de cuidados, mas quem acompanha, quem está passando por esse processo de internação também." (E2) 
“... inclusive as conversas que eu tenho com essa família, eu sempre me coloco a disposição e sempre me coloco no lugar dela" (E1)

\section{b) Atender as demandas e necessidades da família}

As enfermeiras têm a percepção de que adotar o cuidado centrado na família na unidade de trabalho e realizar a entrevista com as famílias utilizando o genograma, possibilita que todos os profissionais disponham de informações e de uma visão ampla das necessidades de cuidado e prioridades da família atendida. Este conhecimento permite que o enfermeiro realize a avaliação e o planejamento da assistência de enfermagem centrada na família, a fim de atender as demandas levantadas.

"... ver alguma demanda que a família trás" (E4)

“... quando dá tempo converso com todo mundo e quando não dá tempo, eu tento focar naquelas pessoas que demonstram uma maior necessidade de atenção e de cuidado" (ER8)

c) Vínculo entre família e equipe

As enfermeiras consideram a importância da inclusão do cuidado centrado na família para o estabelecimento de vínculo entre família e profissional de saúde. O vínculo facilita as relações, a comunicação e a confiança. Formar vínculo com as famílias assistidas na instituição permite um envolvimento recíproco e é benéfico para a construção do cuidado. O genograma é um instrumento que permite que a enfermeira se aproxime da família, fortalecendo o vínculo.

“... é importante que a família esteja acompanhando tudo, pra que crie uma confiança na equipe e vinculo" (E2)

\section{Política da instituição como facilitadora.}

A incorporação do Cuidado Centrado na Família como política da instituição é considerada pelas enfermeiras como essencial para a inserção deste cuidado no processo de trabalho. Elas acreditam que a instituição de saúde promove um ambiente favorável para que o profissional acolha e envolva a família no planejamento da assistência e cuidados prestados a criança doente. As enfermeiras se sentem mais seguras para realizar essa abordagem de cuidado, visto que a ins- tituição, sobretudo a Divisão de Enfermagem é favorável à inserção da família na assistência e reconhece a importância da utilização dos princípios do cuidado centrado na família.

“... nós trabalhamos com cuidado centrado na família desde que eu entrei aqui, o hospital já tem essa política" (E6)

"... a noção que aqui dentro tem, demonstra pra gente o quanto é possível fazer um Cuidado Centrado na Família" (ER8)

\section{Dúvidas e desafios de cuidar das famílias}

Apesar das enfermeiras possuírem conhecimento em relação à importância de incorporar o cuidado centrado na família, elas percebem que incorporar esse cuidado têm sido um desafio, pois os profissionais em geral, estão habituados a prestar assistência centrada no paciente. A falta de conhecimento e habilidades de comunicação para trabalhar com as famílias é uma das dificuldades encontradas para incentivar a participação das famílias no cuidado.

"... eu acho que é um desafio todo dia, a gente fazer esse trabalho de cuidado centrado na família" (E4)

“... eu acho que é um desafio, mas não que eu não me sinta preparada, mas na verdade na prática não é fácil" (E4)

\section{UTILIZANDO 0 GENOGRAMA}

\section{Experiências com a utilização do instrumento}

A utilização do genograma tem sido uma experiência boa e produtiva para grande parte das enfermeiras, pois além de conhecer a família, o instrumento é utilizado também para organizar as informações durante a entrevista. Elas percebem que a família se interessa e disponibiliza mais informações quando é informada sobre a finalidade e é envolvida na construção do genograma. Entretanto, as enfermeiras vivem esta experiência como um desafio, motivadas pela dinâmica da unidade de trabalho e a dificuldade em coletar as informações, além da falta de conhecimento para a utilização do genograma na prática clínica. A ausência dos pais na unidade de terapia intensiva neonatal também foi considerada um desafio para a construção do genograma na prática clínica. 
A utilização do genograma tem sido uma experiência boa e produtiva para grande parte das enfermeiras, pois além de conhecer a família, o instrumento é utilizado também para organizar as informações durante a entrevista.

"... tem sido interessante, assim, até tranquilo" (E1)

"... acho que tem sido bastante produtivo" (E4)

As enfermeiras vivem esta experiência como um desafio, decorrente da dinâmica da unidade de trabalho e da dificuldade em coletar as informações, além da falta de conhecimento para a utilização do genograma na prática clínica.

"... tem sido assim um desafio" (ER7)

\section{Construção do genograma}

Na experiência vivida pelas enfermeiras, o instrumento é construído para todas as famílias internadas nas unidades pediátricas. Em certas situações o genograma é construído em um momento em que a dinâmica da unidade de trabalho permitia. Entretanto, algumas enfermeiras referem ter dificuldade em fazer o genograma em certas unidades devido a rotina da unidade de trabalho.

"... utilizo para todas as famílias" (E2)

"... o genograma agora a gente usa pra todas as famílias" (E4)

\section{Momento em que faz a construção do genograma}

As enfermeiras escolhem preferencialmente o momento da admissão, da entrevista com as famílias para coletar as informações para a construção do genograma. A construção do genograma pode ser iniciada a partir do primeiro contado do profissional com a família, mas novas informações podem ser coletadas através de todos os contatos com a família.

"Eu faço na admissão, na primeira, no primeiro contado que eu tenho com a família, na entrevista, eu linko a entrevista com o genograma" (E1)

Se a enfermeira considera que no momento em que o paciente é admitido na unidade não é possível coletar as informações necessárias, ou, se a família demonstra resistência em transmitir as informações necessárias, ela escolhe outro período em que a dinâmica da unidade permita, ou quando é estabelecido um maior vínculo com a família.
“... você vai fazendo o vínculo com a mãe e acaba perguntando muito mais coisas, e ela fica muito mais aberta a falar também" (E3)

“... se na admissão a gente não consegue fazer, a gente faz num segundo momento assim que for possível devido a dinâmica da unidade" (E4)

A condição da criança também interfere no momento da construção do genograma. Na unidade de terapia intensiva pediátrica, as enfermeiras realizam a construção do genograma com a família, quando a criança está mais estável e a família mais adaptada ao ambiente.

“... na UTI esse genograma acaba ficando mais arrastado, num momento mais tranquilo na verdade, quando a criança já está mais estável" (ER8)

\section{Utilização do genograma para o planejamento da assistência}

As informações coletadas na construção do genograma são utilizadas pelas enfermeiras para realizar o planejamento da assistência de enfermagem, avaliando as demandas da família e intervindo de modo a atender as necessidades individuais daquela família. O genograma é utilizado para conhecer a rede de apoio familiar e com quem o cuidado daquela criança poderá ser compartilhado. O genograma é também utilizado para a elaboração do plano de alta do paciente, pois a partir do instrumento, é possível identificar as pessoas que poderão auxiliar no cuidado da criança no domicílio.

“... acho que a gente usa, acaba usando no dia a dia no planejamento da assistência mesmo" (E4)

\section{VANTAGENS DO USO DO GENOGRAMA}

Como principais vantagens do uso do genograma na prática clínica, as enfermeiras consideram que o instrumento permite que o profissional possua conhecimento da estrutura familiar, suas relações internas e externas, dinamicidade, rede de apoio e suporte familiar, além do conhecimento da história da família, permitindo que as necessidades e demandas familiares possam ser identificadas.

"conhecer a estrutura dessa família, se essa mãe, se eu perceber que ela está com alguma necessidade, alguma demanda" (E1) 
"conhecer a família, sem dúvidas" (ER8)

"posso ver quem são as pessoas mais próximas, que poderiam ajuda-la e levar isso até ela, mostrar o genograma e falar olha, tem essa pessoa, essa, aquela, será que essas aqui não poderiam te ajudar" (E1)

"conseguir ver melhor e conhecer melhor as necessidades daquela família, e até como lidar, como trabalhar, com que linguagem falar" (E4)

"conhecer a história do paciente né, não só em relação ao quadro clínico, como, também a parte social" (E2)

"a gente entendendo melhor o contexto familiar, pode prestar um cuidado assim, mais especifico" (E2)

“... posso ver quem são as pessoas mais próximas, que poderiam ajudá-la e levar isso até ela, mostrar o genograma e falar 'olha, tem essa pessoa, essa, aquela, será que essas aqui não poderiam te ajudar?'" (E1)

\section{BARREIRAS E DESAFIOS PARA $O$ USO DO GENOGRAMA}

Por ser uma experiência nova para algumas enfermeiras, a utilização desta ferramenta é percebida às vezes com certa resistência e dificuldade, sendo a principal dificuldade apontada o tempo para a construção do genograma, além da falta de conhecimento para lidar com as situações que envolvem a sua construção e utilização.

\section{Resistência da família em transmitir informações}

Uma barreira ou desafio identificado para o uso do genograma é a resistência da família em transmitir as informações necessárias para a construção do genograma. Criar um ambiente em que a família se sinta acolhida e que facilite a comunicação é importante para que a família se sinta confortável para transmitir as informações necessárias. Essa resistência pode acontecer se o familiar responsável em fornecer as informações não foi devidamente orientado sobre a finalidade do genograma.

“... a gente tem muito, muita resistência, até por parte do próprio acompanhante" (E1)

“... dependendo da situação, ele não, o acompanhante não se sente à vontade de responder as perguntas, ou responde de forma muito objetiva e tem bloqueio pra que você consiga mais informações" (E1)

\section{Sentimento de invasão de privacidade}

As enfermeiras às vezes não se sentem confortáveis em algumas situações para realizar a construção do genograma com a família, pois frequentemente sentem que estão invadindo a privacidade das famílias. Esse sentimento é causado pela quantidade de perguntas relacionadas à família que os profissionais precisam realizar para a construção do genograma, e as enfermeiras não sabem onde ou como utilizar essas informações para a avaliação e planejamento da assistência do cuidado.

“... muitas vezes a gente se sente um pouquinho invasivo" (E4)

“... muitas vezes dá a sensação de que a gente está invadindo o espaço da família, querendo saber muita coisa e não vai fazer nada com aquela informação" (ER8)

\section{Não inserção do genograma pela totalidade dos enfermeiros}

Outro aspecto percebido pelas profissionais é a dificuldade em inserir o genograma na rotina de trabalho. A falta de conhecimento sobre a importância do uso, construção e utilização do genograma na prática clínica são motivos que impedem que a enfermeira introduza o genograma na sua prática. A percepção de falta de treinamento continuado oferecido pela instituição também contribui para que essa atividade não seja exercida regularmente pela profissional.

"... pra ser sincera não costumo fazer" (E2)

“... mas assim eu não tenho conseguido colocar em prática, sinceramente falando" (E2)

\section{Falta de tempo para a realização do genograma}

As enfermeiras consideram que uma dificuldade para a inserção do genograma na rotina de trabalho é o tempo que será gasto com essa atividade, levando em conta o número de atividades exercidas pela enfermeira e o número reduzido de pessoal. Ao mesmo tempo, algumas enfermeiras acreditam que é possível não levar mais tempo do que o necessário durante a entrevista de admissão para a coleta das informações necessárias para a construção do genograma. 
“... acho que o tempo que a gente gasta não é muito,é uma coisa que dá pra por sim em prática" (E4)

“... como a rotina, ela tem muitas atividades né, durante o período de plantão, é muito difícil você parar e fazer esse genograma" (ER7)

\section{Dificuldades para a inclusão do genograma no processo de trabalho.}

As dificuldades identificadas na inserção do genograma no processo de trabalho consistem em resistência do profissional, falta de conhecimento do instrumento e como aplicar na prática, reconhecer o melhor momento para a coleta das informações, principalmente durante a admissão, sobretudo quando as famílias estão preocupadas com a criança e em algumas situações pouco receptivas para transmitir as informações necessárias.

Importante destacar a dificuldade relacionada à rotina da unidade. A unidade de terapia intensiva é o local onde as enfermeiras menos conseguem inserir o genograma em sua rotina de trabalho, devido à complexidade do cuidado e as diversas atividades que precisam executar em seu período de trabalho.

"Eu não tenho dificuldade pra incluir o genograma no meu processo de trabalho" (E1)

“... mas na inserção do genograma, eu achei que foi fácil, não vi muita dificuldade" (E4)

"Eu acho que a falta de conhecimento, e, de como aplicar" (E2)

\section{Falta de treinamento continuado}

Para superar as dificuldades, as enfermeiras acreditam que deve aumentar o número de treinamentos pela instituição de saúde. Esses treinamentos poderiam abordar a importância do genograma, a utilização na prática, as informações que devem ser coletadas para a construção do genograma. Com os treinamentos, as enfermeiras acreditam que poderão desenvolver mais habilidades de comunicação com as famílias.

"... mais treinamento" (E3)

"A gente faz de todo mundo, só que como faz automático, faz de todo mundo na hora da admissão, a gente acaba usando pouco essa informação, faz porque tem que cumprir rotina, vai lá coloca no programa e ninguém usa muito essa informação" (E4) "a gente tinha sim que utilizar melhor esse instrumento" (E4)

\section{Discussão}

Este estudo permitiu a identificação de quatro categorias importantes em relação à percepção e vivência do enfermeiro quanto ao cuidado centrado na família e à utilização do genograma no processo de trabalho.

A percepção das enfermeiras sobre o cuidado centrado na família é coerente com a literatura que indica que cuidar das famílias, atender as suas necessidades e demandas é fundamental no cotidiano de trabalho do enfermeiro. É necessário que o profissional amplie o seu foco para além do cuidado com a criança, mas também às necessidades e demandas da família, considerando a diversidade e complexidades das dinâmicas familiares e a realidade social, econômica e cultural dessa família.

Em nosso estudo, identificou-se que as enfermeiras consideram importante o estabelecimento de vínculo com a família e que o genograma potencializa este vínculo, o que apresenta relação com a literatura ao destacar que trabalhar com famílias, é estabelecer um ambiente de confiança mútua. ${ }^{(2,8)}$

Estudos mostram que o genograma é um instrumento utilizado pelos enfermeiros para que exista uma aproximação e se inicie vínculo entre o profissional e a família. O uso desse instrumento facilitou o envolvimento da criança e sua família, facilitando a relação com os profissionais. ${ }^{(4)}$

$\mathrm{O}$ vínculo é uma importante ferramenta para o cuidado apropriado e integral. Formar vínculo aproxima e permite o envolvimento recíproco entre os sujeitos. Fortalecer este vínculo é de extrema importância para os profissionais de saúde e o paciente, pois permite que a construção do cuidado seja por meio de uma relação de confiança. ${ }^{(9)}$

O apoio e a política da instituição, identificada neste estudo, como facilitadora, para a inserção desse cuidado no processo de trabalho cotidiano, é também reiterada pela literatura.

Dentro das organizações de saúde, é importante que existam políticas flexíveis, procedimentos e práticas que sejam pertinentes as necessidades e valores da criança e da família, permitindo que possam fazer escolhas no cuidado.(10) 
O estudo identificou aspectos de dúvidas quanto à construção do genograma e desafios vivenciados pelas enfermeiras na articulação das informações do genograma ao cuidado das famílias.

Pesquisas revelam que os enfermeiros possuem dificuldades em apoiar e incentivar a participação dos pais por diversos motivos, como a preocupação sobre as habilidades dos pais realizarem o cuidado, a responsabilização, se sentir intimidado pelos pais e medo em perder o controle e autoridade. Outros estudos mostram que os enfermeiros incentivam a participação dos pais, pois consideram uma oportunidade de ensino e supervisão, mas ainda possuem dificuldades relacionadas à falta de habilidades de comunicação. ${ }^{(11)}$

Em relação à experiência de utilização do genograma, nosso estudo identificou quatro subcategorias, onde a primeira aborda a experiência do enfermeiro em relação ao uso do genograma no seu processo de trabalho. Para a grande maioria dos enfermeiros a utilização do genograma tem sido uma experiência boa, pois o instrumento permite que o enfermeiro obtenha uma visão geral da estrutura familiar, permite a aproximação do profissional e da família, tornando a comunicação mais livre. A literatura também indica que o genograma é considerado um instrumento de fácil aplicação, pois permite uma visão ampla das relações familiares. ${ }^{(12)}$

Quanto a construção do genograma, nosso estudo revelou que as enfermeiras utilizam esse instrumento para quase todas as famílias. Utilizar o genograma durante a entrevista familiar permite que o enfermeiro obtenha compreensão e vínculo com família, e conheça de forma geral a estrutura familiar. ${ }^{(12)}$

Quando se trata do momento em que o genograma pode ser construído, coerente com nosso estudo, a literatura indica que a construção do genograma pode ser iniciada a partir do primeiro contato do enfermeiro com a família, as informações para o genograma podem ser coletadas através da entrevista com as famílias. ${ }^{(12)}$

A abordagem à família durante a construção do genograma, deve ser uma abordagem ativa e confiante, as perguntas devem ser intencionais para estimularem a coleta de informações, possibilitando a avaliação familiar. ${ }^{(8)}$

Quanto ao uso do genograma no planejamento da assistência de enfermagem, identificamos que a maioria dos enfermeiros realiza essa atividade a partir das informações obtidas no genograma.
O genograma é um instrumento desenvolvido como ferramenta utilizada na avaliação, planejamento e intervenção. Após a avaliação da família utilizando as informações do genograma, o enfermeiro determina se a intervenção será necessária e de que forma poderá intervir para auxiliar nas mudanças nos domínios afetivos, cognitivos e comportamentais de um funcionamento familiar, ou propor intervenções as famílias. ${ }^{(12)}$

A terceira categoria relaciona-se às vantagens da utilização do genograma pela enfermeira em seu cotidiano de trabalho, onde foram identificadas a seguintes subcategorias: estrutura familiar, dinâmica familiar, necessidades da família, história do paciente e rede de apoio familiar, que são coerentes com o que a literatura apresenta.

Estudos mostram que o uso do genograma durante a entrevista permite que o enfermeiro conheça a estrutura da família, as suas relações internas e externas, os vínculos emocionais entre os membros e pessoas de fora da família os seus pontos de apoio, além da identificação das necessidades da família, e o contexto em que cada família é exposta. Permite a utilização dessas informações no planejamento da assistência. ${ }^{(2,4)}$

Quanto às barreiras e desafios para o uso do genograma, este estudo indicou a resistência do familiar em transmitir as informações, sentimento de invasão de privacidade, não inserção do genograma pela totalidade dos enfermeiros, falta de tempo para a realização do genograma e dificuldades para a inclusão do genograma no processo de trabalho. Estudo revela que durante a entrevista e construção do genograma, as famílias se apresentaram receptivas em falar e expor as suas emoções, medos e dificuldades. ${ }^{(13)}$ Já um outro estudo identificou que a construção do genograma só foi possível após o profissional estabelecer um vínculo com a família. ${ }^{(4)}$ Durante a construção do genograma, é possível criar um ambiente que se estabeleça uma relação recíproca com a família, proporcionando que estes se sintam acolhidos e valorizados ao estarem contribuindo para a realização da atividade, procurando mostrar o que é e como funciona o instrumento, pois isso facilita a interação e comunicação com a família, criando vínculo e confiabilidade para as informações fluírem. ${ }^{(14)}$

Achados deste estudo destacam a necessidade de aumento do número de treinamentos oferecidos pela instituição de saúde às enfermeiras, para superar as di- 
ficuldades vivenciadas e possibilitar treinamento de habilidades e reflexão para os enfermeiros. Estudo destaca que com a melhora dos treinamentos e educação, os enfermeiros terão um melhor comportamento frente às famílias, garantindo que o cuidado centrado na família seja incorporado de forma consistente. Os enfermeiros devem ter o seu trabalho com as famílias reconhecido e recompensado nas avaliações de desempenho. ${ }^{(11)}$

Quando os enfermeiros recebem treinamento e desenvolvem habilidades de comunicação com as famílias, isto faz com que se sintam mais confiantes, melhorando a relação entre enfermeiro e profissional, tornando essa relação mais aberta, recíproca, atenciosa e respeitosa. A utilização deste instrumento deve estar associada ao conhecimento técnico-científico e habilidades de comunicação e observação. O processo de construção do genograma é dinâmico, requer atualização ao longo do tempo. . $^{(14,15)}$

\section{Conclusão}

Este estudo revelou que as enfermeiras consideram importante a implementação do cuidado centrado na família em sua rotina e unidade de trabalho, considerando-se as vantagens que esta abordagem de cuidado traz para o paciente, a família, os profissionais e o serviço de saúde. Ao mesmo tempo, também revelou a importância da utilização do genogramas na entrevista com as famílias e os desafios vividos pelas enfermeiras e aponta para estratégias para superação das dificuldades para implantação do uso mais efetivo desta ferramenta na prática clínica. O genograma ainda é um instrumento pouco utilizado pela enfermagem brasileira, e isso pode ser um desafio na inserção plena deste instrumento na prática clínica. A falta de conhecimento sobre a importância da utilização do genograma para a avaliação das famílias, sobre a sua construção e aplicação na prática e tímidas habilidades de comunicação com as famílias, podem ser barreiras para a utilização desse instrumento pelos enfermeiros em sua rotina de trabalho. É importante que os serviços de saúde incentivem o uso do genograma e promovam treinamentos e educação continuada em relação ao instrumento e ao cuidado centrado na família, permitindo que os enfermeiros desenvolvam o conhecimento técnico que potencialize a sua comunicação com as famílias e aumente a autoconfiança para realizarem o cuidado centrado na família. É indispensável que o serviço de saúde disponha de políticas que incluam o cuidado centrado na família em seus processos assistenciais, o que impactará em práticas clínicas, instrumentos, protocolos e documentos institucionais padronizados, que direcionem a prática profissional cotidiana orientada para o cuidado centrado na família.

\section{Contribuições}

Vale CC, Santos NC e Angelo M contribuíram com a concepção do estudo, análise e interpretação dos dados, redação do artigo, revisão crítica relevante do conteúdo intelectual e aprovação da versão final a ser publicada.

\section{Referências}

1. Wright LM, Leahey M. Enfermeiras e famílias: um guia para avaliação e intervenção na família. 5th ed. São Paulo: Roca; 2012.

2. Rumor PC, Boehs AE. 0 impacto da hospitalização infantil nas rotinas das famílias monoparentais. Rev Eletr Enf. 2013;15(4):1007-15.

3. Costa SF, Oliveira RC, Monteiro GR, Fernandes MA, Zaccara AA, Morais GS, et al. Family structure assessment of patients in palliative home care. Int Arch Med. 2016;9:230.

4. Nascimento LC, Dantas IR, Andrade RD, Mello DF. Genograma e ecomapa: contribuições da Enfermagem Brasileira. Texto Contexto Enferm. 2014;23(1):211-20.

5. Davidson JE, Aslakson RA, Long AC, Puntillo KA, Kross EK, Hart J, et al. Guidelines for familycentered care in the neonatal, pediatric, and adult ICU. Crit Care Med. 2017;45(1):103-28.

6. Turato ER. Métodos qualitativos e quantitativos na área da saúde: definições, diferenças e seus objetos de pesquisa. Rev Saúde Pública. 2005;39(3):507-14.

7. Bardin L. Análise de conteúdo. Lisboa: Edições 70; 2014.

8. Schwartz E, Lange C, Meincke SM, Heck RM, Kantorski LP, Gallo CC. Avaliação de famílias: ferramenta de cuidado de enfermagem. Cienc Cuid Saude. 2009;8(Supl):117-24.

9. Nogueira AP, Lucena KD, Pinto BP, Araújo MF, Ataíde MC, Pedrosa Neto WD, et al. A importância do uso do genograma para compreensão da dinâmica familiar. Rev Enferm UFPE. 2017;11(12):5110-5.

10. Sellán AV, Soto MC, Martínez ML. Family-centered care: a philosophy to be developed. Pediatr Neonatal Nurs Open J. 2017;4(2):24-28.

11. Coyne I, O'Neill C, Murphy M, Costello T, O'Shea R. What does family-centred care mean to nurses and how do they think it could be enhanced in practice. J Adv Nurs. 2011;67(12),2561-73

12. Christoffel MM, Pacheco ST, Reis CS. Modelo Calgary de avaliação da família de recém-nascidos: estratégia pedagógica para alunos de enfermagem. Esc Anna Nery. 2008;12(1):160-5.

13. Botelho LR, Anísio NF, Cruz AC, Santos NC,Angelo M. Autoavaliação da inclusão das famílias em políticas e práticas institucionais: perspectiva da equipe de enfermagem. Esc Anna Nery. 2018;22(4):e20180207

14. Mello DF, Viera CS, Simpionato E, Biasoli-Alves ZM, Nascimento LC. Genograma e Ecomapa: possibilidades de utilização na estratégia de saúde da família. Rev Bras Cresc Desenv Hum 2005;15(1):78-89.

15. Duhamel F, Dupuis F, Turcotte A, Martinez AM, Goudreau J. Integrating the illness beliefs model in clinical practice: a family systems nursing knowledge utilization model. J Fam Nurs. 2015;21(2):322-48. 